Characterization of an Enriched Uranyl Fluoride Deposit in a Valve and Pipe Intersection Using Time-of-Flight Transmission Measurements with ${ }^{252} \mathrm{Cf}$

$$
\text { CONF-980733-- }
$$

\author{
M. S. Wyatt ${ }^{+}$ \\ T. Uckan \\ J. T. Mihalczo \\ T. E. Valentine \\ Oak Ridge National Laboratory ${ }^{*}$ \\ P.O. Box 2008 \\ Oak Ridge, TN 37831-6004 \\ (423) 574-0284 \\ T. F. Hannon \\ East Tennessee Technology Park \\ P.O. Box 2003 \\ Oak Ridge, Tennessee 37831
}

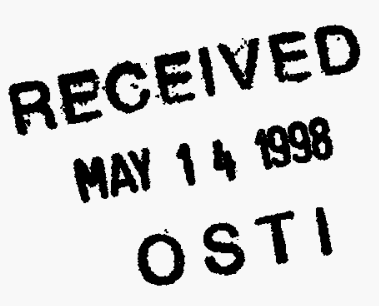

Presented at the

Institute of Nuclear Materials Management Meeting

July $26-30,1998$

Naples, Florida
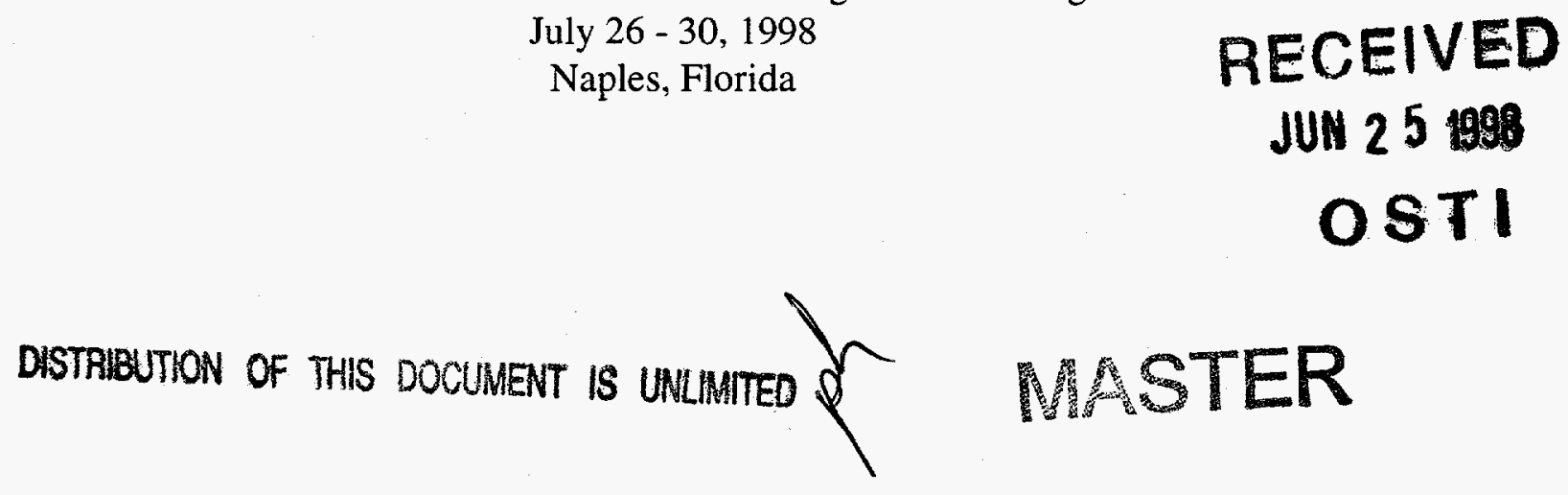

\footnotetext{
* Managed by Lockheed Martin Energy Research Corporation for the U.S. Department of Energy under contract DEAC05-96OR22464.
} 


\section{DISCLAIMER}

This report was prepared as an account of work sponsored by an agency of the United States Government. Neither the United States Government nor any agency thereof, nor any of their employees, makes any warranty, express or implied, or assumes any legal liability or responsibility for the accuracy, completeness, or usefulness of any information, apparatus, product, or process disclosed, or represents that its use would not infringe privately owned rights. Reference herein to any specific commercial product, process, or service by trade name, trademark, manufacturer, or otherwise does not necessarily constitute or imply its endorsement, recommendation, or favoring by the United States Government or any agency thereof. The views and opinions of authors expressed herein do not necessarily state or reflect those of the United States Government or any agency thereof. 


\section{DISCLAIMER}

Portions of this document may be illegible electronic image products. Images are produced from the best available original document. 


\title{
Characterization of an Enriched Uranyl Fluoride Deposit in a Valve and Pipe Intersection Using Time-of-Flight Transmission Measurements with ${ }^{252} \mathrm{Cf}$
}

\author{
M. S. Wyatt \\ The University of Tennessee \\ Department of Nuclear Engineering \\ Knoxville, TN 37996-2300 \\ T. Uckan, J. T. Mihalczo, and T. E. Valentine \\ Oak Ridge National Laboratory \\ P.O. Box 2008 \\ Oak Ridge, Tennessee 37831-6004 \\ T. F. Hannon \\ East Tennessee Technology Park \\ P.O. Box 2003 \\ Oak Ridge, Tennessee 37831
}

\begin{abstract}
A method was developed and successfully applied to characterize large uranyl fluoride $\left(\mathrm{UO}_{2} \mathrm{~F}_{2}\right)$ deposits at the former the Oak Ridge Gaseous Diffusion Plant. These deposits were formed by a wet air in-leakage into the $\mathrm{UF}_{6}$ process gas lines over a period of years. The resulting $\mathrm{UO}_{2} \mathrm{~F}_{2}$ is hygroscopic, readily absorbing moisture from the air to form hydrates as $\mathrm{UO}_{2} \mathrm{~F}_{2}-\mathrm{nH}_{2} \mathrm{O}$. The ratio of hydrogen to uranium can vary from $0-16$, and has significant nuclear criticality safety impacts for large deposits. In order to properly formulate the required course of action, a non-intrusive characterization of the distribution of the fissile material within the pipe, its total mass, and amount of hydration was necessary. The Nuclear Weapons Identification System ' (NWIS) previously developed at the Oak Ridge Y-12 Plant for identification of uranium weapons components in storage containers was used to successfully characterize these deposits.
\end{abstract}

\section{Background}

The characterizations were performed by active neutron and gamma ray time-of-flight transmission measurements through the pipe where the effects of prompt gamma rays and $8 \mathrm{MeV}$ prompt neutrons from ${ }^{252} \mathrm{Cf}$ fission are separated in time. This methodology to non-intrusively characterize $\mathrm{UO}_{2} \mathrm{~F}_{2}$ deposits was first applied to a large deposit at the former Oak Ridge Gaseous Diffusion Plant, now the East Tennessee Technology Park. This deposit existed in a 17-ft.-long, 24-in.-O.D. process gas line that because of its shape became to be known as the "Hockey Stick" deposit (Figure 1). The deposit was formed as a result of a steady wet air in-leakage over a number of years from the 20-in.-dia. double disc gate valve visible in the picture. In order to properly assess the nuclear 


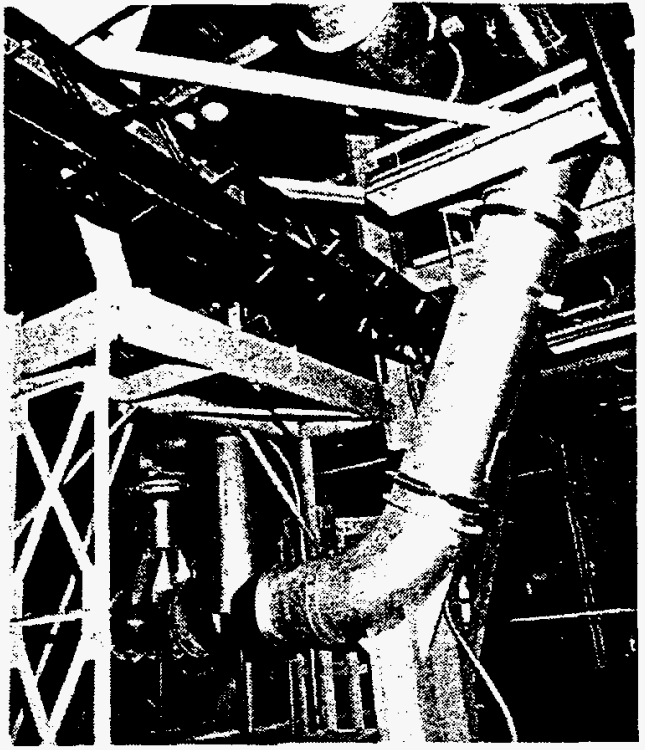

Figure 1. The "Hockey Stick" deposit and the 20-in-dia. double disc gate valve which was the source of the wet air in-leakage. criticality safety requirements and to provide information that would allow formulation of a safe method to remove the deposit, a characterization of the deposit distribution, its hydration, and total mass was necessary. Contrary to expectations, measurement results indicated that in portions of the pipe the deposit had adhered to the top of the pipe with very little material existing on the bottom. The measurement findings were in exceptional agreement to the later intrusive findings as exemplified by the results at one location along the pipe as shown in Figures 2 and 3. Based on the success of this work two more deposit locations were characterized, and are the subject of this paper.

\section{Deposit Descriptions}

The two additional deposits existed in two separate locations of the process gas system. The first deposit was believed to exists in the upper internals (around the valve stem and bellows) of a 20 -in.-dia. double disc gate valve, and is shown in Figure 4a. The valve bonnet

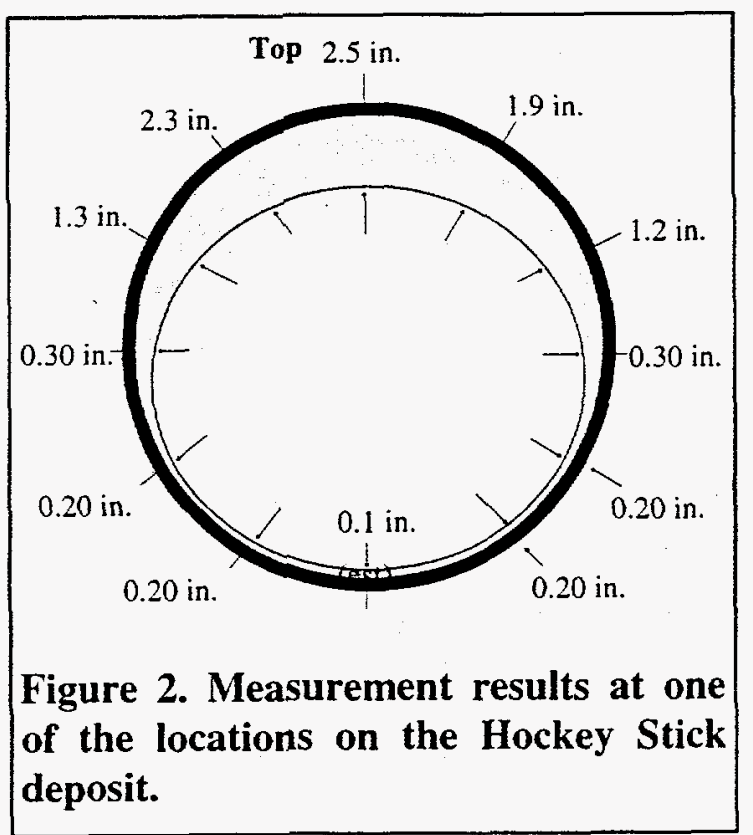

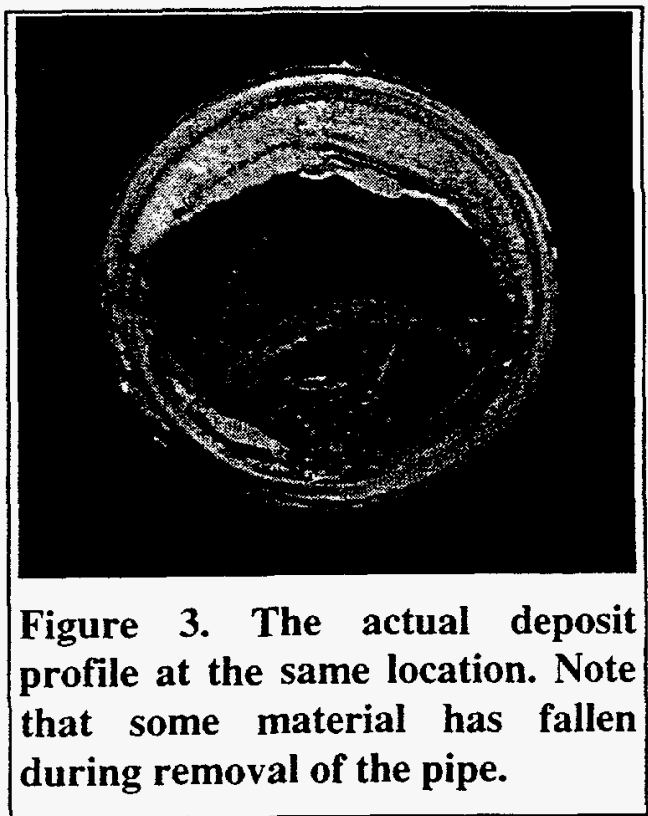

surrounding the internals has an O.D. of $24 \mathrm{in.} \mathrm{and} \mathrm{a} \mathrm{height} \mathrm{of} 36 \mathrm{in}$. The second deposit existed in a pipe intersection consisting of a $10 \mathrm{ft}$ long 30 -in.-dia. horizontal pipe and a $12 \mathrm{ft}$ long 24-in.-dia. vertical pipe joined via a custom fabricated transition piece (T-Pipe), and is shown in Figure $4 b$. 
Previous passive Non-Destructive Assay (NDA) measurements using gamma ray spectrometry and neutron counting indicated that the block valve contained approximately $156 \mathrm{~kg} \pm 78 \mathrm{~kg}$ of material enriched to $3.3 \mathrm{wt} \% \pm 0.66 \mathrm{wt} \%{ }^{235} \mathrm{U}$ and the T-Pipe contained approximately $240 \mathrm{~kg} \pm 120 \mathrm{~kg}$ of material enriched to $3.4 \mathrm{wt} \% \pm 0.68 \mathrm{wt} \%{ }^{235} \mathrm{U}$. Deposits of this magnitude are a significant nuclear criticality safety concern since under optimal conditions the minimum critical mass is $102 \mathrm{~kg}$ for $\mathrm{UO}_{2} \mathrm{~F}_{2}(3 \%)$ and $55.5 \mathrm{~kg}$ for $\mathrm{UO}_{2} \mathrm{~F}_{2}(4 \%){ }^{2}$ The primary concern in the $\mathrm{T}$-pipe was the material distribution. If the majority of the deposit was located in the transition piece or the vertical pipe, any disturbance of the material could cause the deposit to fall and collect directly below in the horizontal pipe and possibly cause a nuclear criticality accident. The large deposit in the Hockey Stick interferes with the gamma ray spectrometry measurements on the valve and required a second confirmatory measurement. A non-intrusive characterization of the distribution of the fissile material within the pipe and valve, their total mass, and amount of hydration was required.

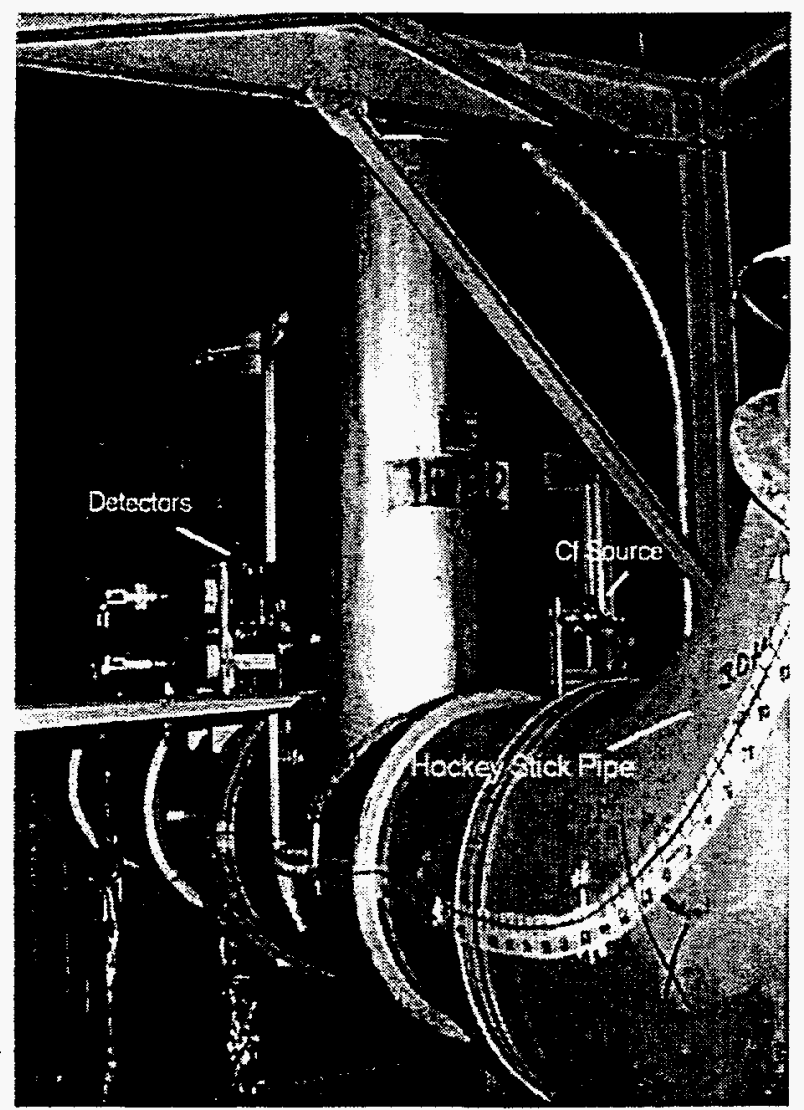

Figure 4a. The 20" block valve, shown with the ${ }^{252} \mathrm{Cf}$ source and detectors in place. The "Hockey Stick" deposit is on the right, approximately $30^{\prime \prime}$ from the valve.

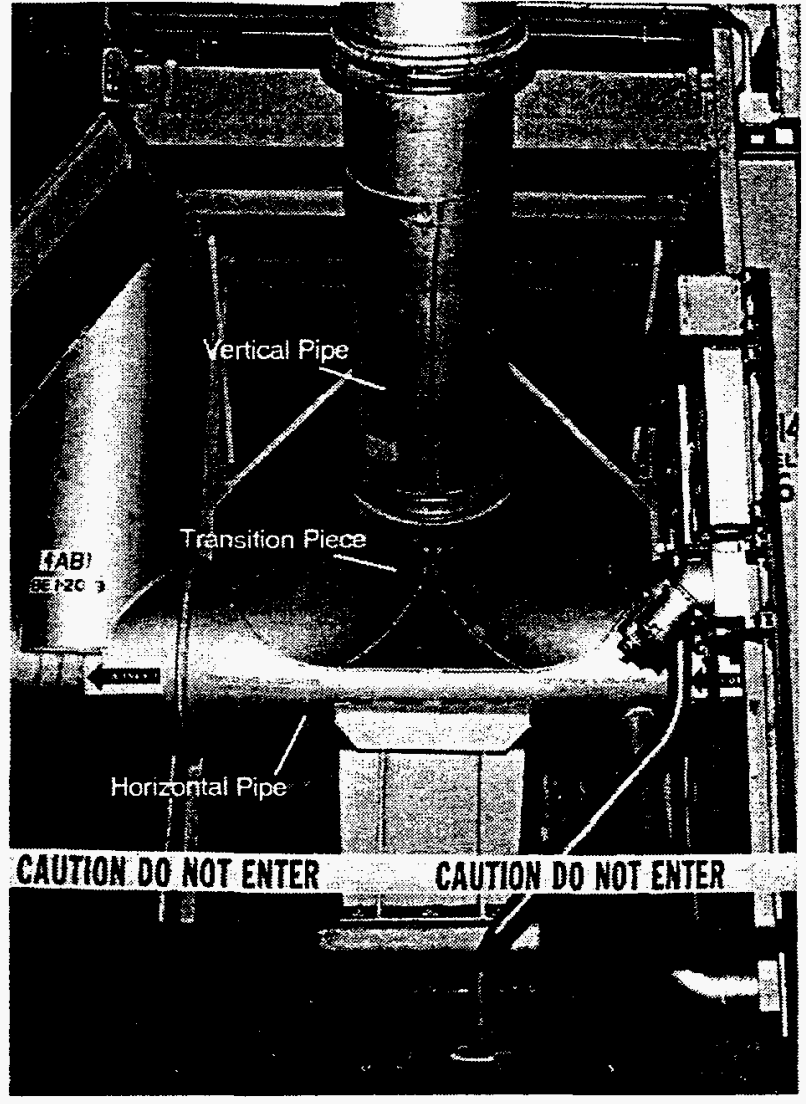

Figure 4b. The "T-Pipe" is a 30" O.D. horizontal pipe conjoined to a $24 "$ "O.D. vertical pipe via a custom transition piece. Note the large support structure under the bottom of the horizontal pipe. 
Instrumentation and Measurement Theory

Briefly, NWIS consists of an external ${ }^{252} \mathrm{Cf}$ source in a parallel plate ionization chamber, two or more fast plastic scintillation detectors for measuring the arrival of neutrons and gamma's, a custombuilt PC based 5 channel data acquisition and control board that has a sampling capability of up to 1 $\mathrm{GHz}$, and a standard $\mathrm{PC}$ to process and display the data. The ${ }^{252} \mathrm{Cf}$ ionization chamber serves as a timed source of spontaneous fission neutrons and gamma's. Neutrons and gamma's emitted from the fission event either traverse the pipe and deposit with no interaction (transmission), are scattered within the material, or initiate the fission chain multiplication process. The detectors measure the time distribution of counts that occur after the initiating fission in the source. Since the time of fission is marked by the pulse from the source ionization chamber, the energy of the neutron is determined from the measured time it takes to travel the known distance between the source and detector using the non-relativistic kinetic energy equation - a neutron time-of-flight (TOF) measurement. Gamma rays that are directly transmitted travel the same speed regardless of energy, thus their arrival at the detector after fission is based solely on the separation between the source and detector. Gamma rays that are scattered arrive later in time than those that are directly transmitted, in essence providing a collimated source without having to heavily shield the detector, i.e., collimation by timing rather than lead. The method can be applied in high background radiation areas, since any background radiation is uncorrelated in time with the source. The time correlated signature is equivalent to the right half of the cross-correlation function between the source and detector and is essentially a randomly pulsed neutron measurement. ${ }^{3}$

As $\mathrm{UO}_{2} \mathrm{~F}_{2}$ hydrates, the material density changes due to the displacement of the dense uranium component by the relatively light hydrogen. The material density can change by about a factor of four over the full range of hydration, making a normal transmission measurement determination of the material properties impossible since neither the density or thickness of the deposit is known. The ${ }^{252} \mathrm{Cf}$ provides a timed source of neutrons and gamma rays yielding two simultaneous measurements.

In the first measurement high energy neutrons $(>8 \mathrm{MeV})$ are used to measure the deposit thickness and construct a profile of the deposit distribution. This is possible because the neutron total interaction cross-section above $6 \mathrm{MeV}$ is essentially flat with hydration, varying by less than 10 percent. Above $1.5 \mathrm{MeV}$ the hydrogen cross-section rolls off sharply leaving the ${ }^{235} \mathrm{U}$ and ${ }^{238} \mathrm{U}$ cross-sections to dominate. However, the relative abundance of the hydrogen. is much greater than the uranium and these two competing effects offset each other, leading to the relatively flat total interaction cross-section as shown in Figure 5. At low energies the total macroscopic cross-section is sensitive not only to slight changes in hydration, but to slight perturbations in the incident neutron energy, denoted by the large separation between the three cross-sections at low energy $(0.5,1.0$ and $1.5 \mathrm{MeV}$ ). At high energies (above $6 \mathrm{MeV}$ ) the cross-sections, in addition to being essentially flat, are only weakly affected by perturbations of the incident neutron energy. This is important since it demonstrates that timing uncertainties in the TOF measurement, which are related to the measured neutron energy, will not have a strong effect on the calculation of material properties. Since the total interaction cross-section (above $6 \mathrm{MeV}$ ) is approximately constant and can be calculated for any hydration (density), the deposit thickness can be determined. 


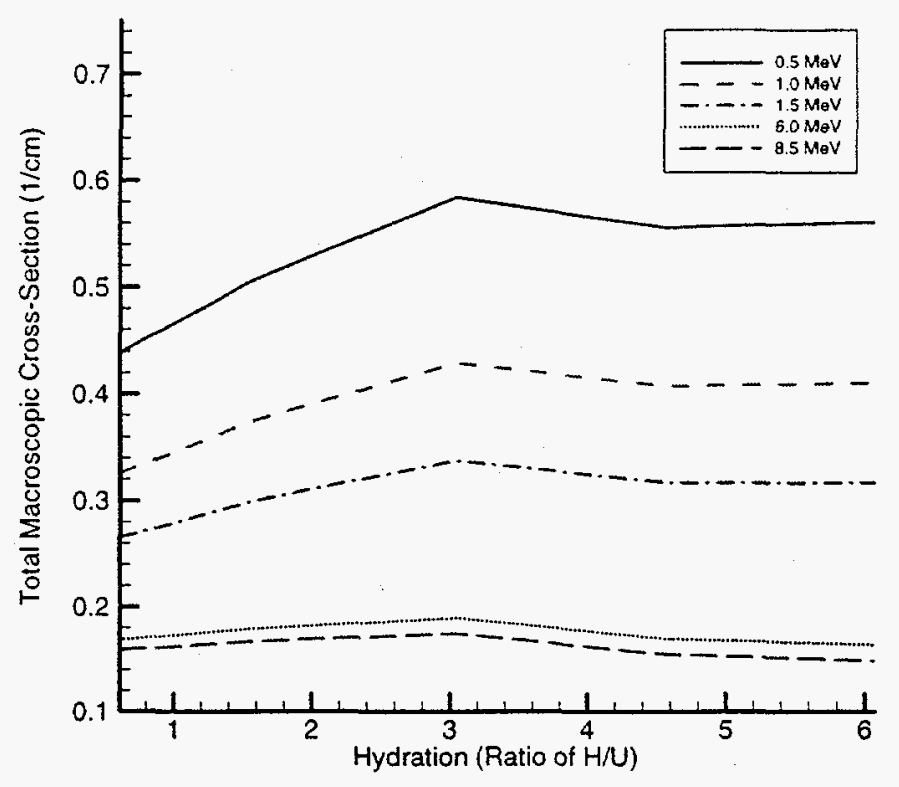

Figure 5. Total Macroscopic Neutron Cross-Sections at $\mathrm{E}=0.5,1.0,1.5,6.0$, and $8.5 \mathrm{MeV}$
The second measurement uses the gamma ray emission spectrum from ${ }^{252} \mathrm{Cf}$ to determine the deposit hydration, which is related to the material density. The gamma ray cross-sections are highly $Z$-dependent, making the measurement well suited for this application. Due to the fast timing resolution of the NWIS system ( $1 \mathrm{nsec}$ ), gamma's that are scattered or interact arrive later in time than those that are directly transmitted, in essence providing a perfectly collimated source used to measure the material mass attenuation coefficient. However, because all transmission gamma rays arrive at the detector at the same time regardless of energy it is necessary to use a fission spectrum-weighted. approach to determine the material properties.

Using the estimate of the deposit thickness obtained from the neutron data, the mass attenuation coefficient is then determined which is distinctly related to the deposit density or hydration.

The measurement results can be then refined by a series of iterative calculations. The process begins by assuming a constant total macroscopic cross-section for neutrons (which in fact varies by about ten percent over the range of hydration). Once the thickness is determined from the neutron portion of the measurement, the hydration is calculated from the gamma portion of the measurement. This hydration is then used to refine the neutron cross-sections and obtain a new thickness from the neutron data. This new estimate of the thickness is then re-applied to the gamma transmission measurement for a new estimate of the hydrogen to uranium ratio, denoted $\mathrm{H} / \mathrm{U}$. This process continues until values of the thickness and hydration are acceptably converged. One caveat to the iterative procedure is that is does not work for thin deposits. The exponential behavior of the transmission gamma rays yield large variations in the mass attenuation coefficient for small uncertainties in the measured deposit thickness. Because the deposit hydration is derived from the mass attenuation coefficient the procedure breaks down.

\section{Measurement Results}

Reference measurements were performed on a clean block valve and T-Pipe in order to remove the contribution of the pipe walls and valve internals from the measurement. Then by performing a series of horizontal, vertical, and rotational scans about the valve and $T$-pipe with the source and detectors the material distribution was determined. In both the valve and the T-Pipe the deposits were very thin, necessitating that the value of $\mathrm{H} / \mathrm{U}$ be estimated by using the results from previous 
measurements on the Hockey Stick. Referring to Figure $4 b$, the inlet valve for the T-Pipe is located on the right and the outlet valve is on the left. Measurements found no significant deposition in the extreme left or middle portion of the horizontal pipe, with exception of a thin coating around the perimeter approximately 0.1 " thick. On the inlet (right) side of the horizontal pipe a roughly annular deposit of 0.25 " to 0.34 " thick was measured. The large support structure and irregular surfaces prevented a thorough investigation of the bottom of the horizontal pipe. In the transition piece no material was noted on the front or rear faces but a deposit approximately 0.2 " thick was found on each of the curved shoulders. The vertical riser contained a annular deposit that tapered from $0.2^{\prime \prime}$ thick near the bottom to 0.1 " thick approximately $75^{\prime \prime}$ up the riser, which was as far as could be measured for safety concerns. Based on the measured material distribution and the $H / U$ value assumed from the Hockey Stick measurements, the estimated material mass was $93 \mathrm{~kg}$. Based on these results it was concluded the T-Pipe could be disturbed without risk of a nuclear criticality accident and it was elected to breach the piping and remove the deposit. Figures $6 \mathrm{a}$ and $6 \mathrm{~b}$ show the deposit distribution in the T-Pipe. The deposit mass removed from the T-pipe, based on gross scale measurements, was $126 \mathrm{~kg}$ which compared favorably to the measured estimate of $93 \mathrm{~kg}$ and was significantly less than the previous estimates of $240 \mathrm{~kg} \pm 120 \mathrm{~kg}$ from gamma ray spectrometry and neutron counting with the T-Pipe assembled.

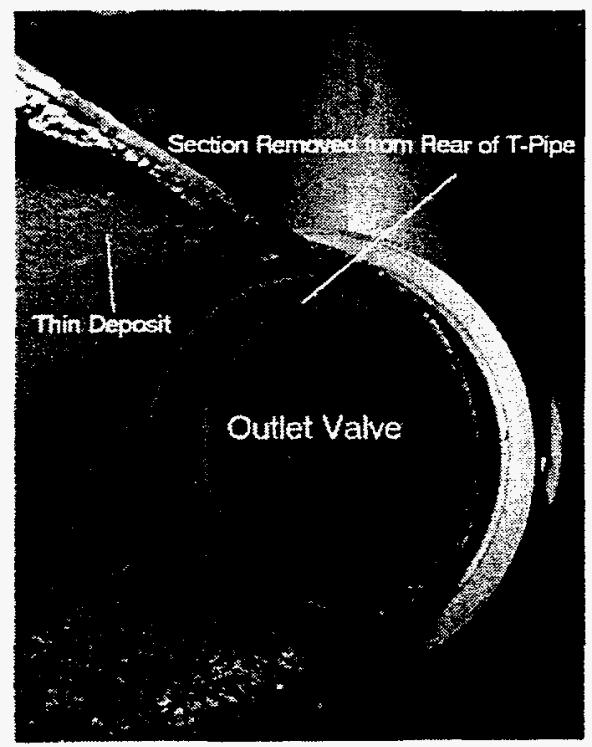

Figure 6a. Deposit removal in T-Pipe shown from the rear. A very thin deposit exists on the pipe wall and some loose material is visible in the bottom.

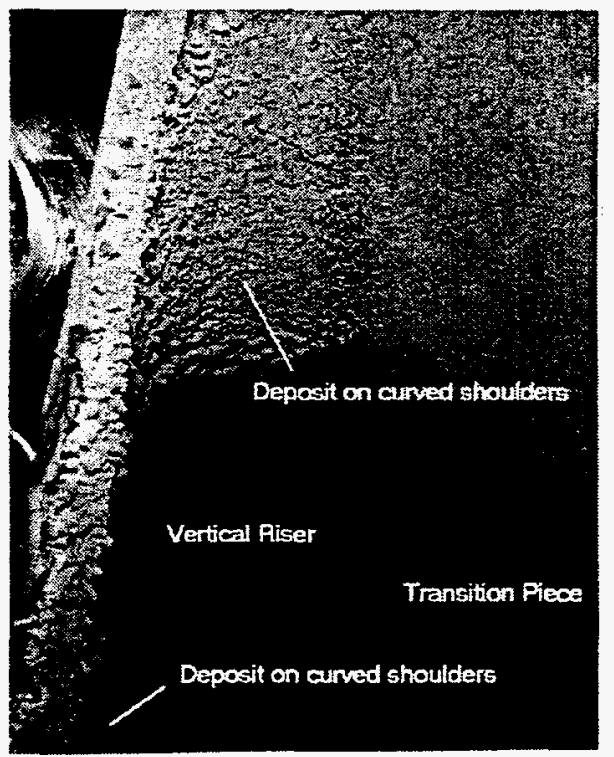

Figure 6b. Looking up the vertical riser of the T-pipe, heaviest deposit is on the curved shoulders of the transition piece, which is rotated $90^{\circ}$ in this picture.

Time constraints associated with project deadlines did not allow for an extensive characterization of the block valve. Only three set of vertical scans were performed by moving the ${ }^{252} \mathrm{Cf}$ source and detectors in conjunction up the valve bonnet in 6" vertical increments. The vertical scans were 
spaced 6" apart on the horizontal; one on the vertical midline of the valve and two on either side spaced $6 "$ apart. The measurements found that the majority of the valve bonnet contained no deposit whatsoever, with the exception of a slight deposition on one edge. Due to the small number of measurements taken from only a single direction it is impossible to reconstruct even a rough image of the material distribution in this area. Assuming a slab-like geometry viewed orthogonally, the measurements indicated 0.1 " to 1.0 " of material was present with an estimated total mass of $13 \mathrm{~kg}$. A normalized representation of the deposit distribution is presented in Figure 7.

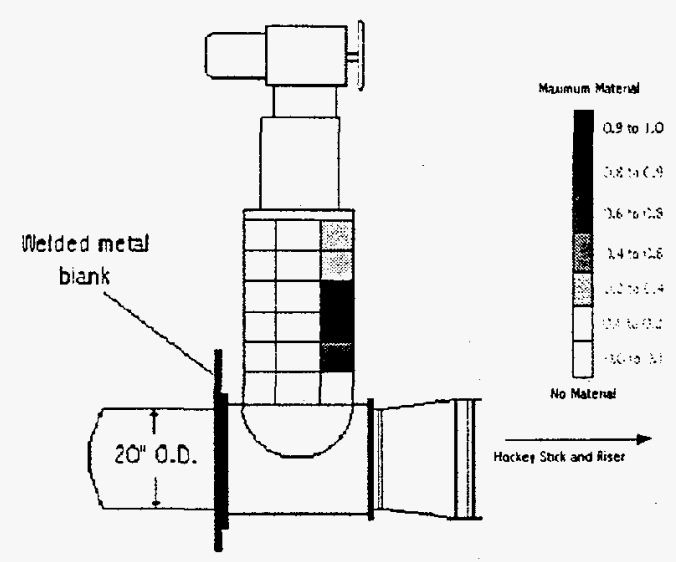

Figure 7. A representation of the deposit distribution in the valve. Note that the distribution has been normalized.

Based on these measurement results it would be impossible to have the $156 \mathrm{~kg}$ $\pm 78 \mathrm{~kg}$ of deposit previously estimated and that most likely even much less material existed. Therefore, the decision was made to forego any deposit removal activities on the valve. At a later date, after the Hockey Stick deposit had been removed which interfered with the gamma spectrometry measurements, NDA personnel re-measured and concluded that it contained less than $14.8 \mathrm{~kg}$ of material.

\section{Conclusions}

It was successfully demonstrated that the Nuclear Weapons Identification System (NWIS) provides a reliable method for non-intrusive characterization of hydrated uranyl fluoride deposits. The characterization can be performed when neither the material mass or density is known, and can be successfully applied in environments where other methods fail due to high background radiation conditions or self-shielding effects. The method can be used to determine the material distribution, the level of hydration, and the total mass of the deposit. This technique may be applied to other $\mathrm{UF}_{6}$ gaseous diffusion plants for deposit measurements, for other types of holdup measurements such as in freezer-sublimers and process gas coolers, or for other processes with nuclear material.

\section{References}

1. Mihalczo, J. T., Valentine, T. E., Mullens, J. A., and Mattingly, J. K., "Physical and Mathematical Description of the Nuclear Weapons Identification System NWIS Signatures," Oak Ridge Y-12 Plant report No. Y/LB-15, 946 R3, September 1997.

2. Jordan, W. C. and Turner, J. C., "Minimum Mass of Moderator Required for Criticality of Homogenous Low-Enriched Uranium Systems", ORNL/CSSD/TM-284, Martin-Marietta Energy Systems, Inc., Oak Ridge National Laboratory, December 1992.

3. Mihalczo, J. T., "Use of ${ }^{252} \mathrm{Cf}$ as a Randomly Pulsed Neutron Source for Prompt Neutron Decay Measurements," Nucl. Sci. Eng., 41, 296 (1970). 